\title{
A Flyback Converter-based Hybrid Balancing Method for Series-Connected Battery Pack in Electric Vehicles
}

\author{
Xiangwei Guo, Member,IEEE, Jiahao Geng, Zhen Liu, Xiaozhuo Xu, Member,IEEE, Wenping Cao, Senior \\ Member,IEEE
}

\begin{abstract}
An active balancing method based on two flyback converters is proposed for series-connected battery pack. Balanced energy can be transferred between the whole battery and any single cell. The proposed topology reduces the number of energy storage components, the volume and the cost of the balancing system. And it has the characteristics of fast balancing speed and high balancing efficiency. Based on the topology, a dual-objective hybrid control strategy is proposed, which can reduce the highest voltage and boost the lowest voltage in the charging or discharging process of the cells in one sampling period, so as to improve the balancing speed. Simulation and experimental results show that the proposed method has a good balancing effect and can significantly improve the consistency of series battery pack. This work is potentially significant in terms of improved reliability of battery packs and savings of costs and lives in safety-critical applications.
\end{abstract}

Index Terms-Active balancing, flyback converter, series battery pack, dual-objective control.

\section{INTRODUCTION}

$\mathrm{L}$ ITHIUM-ION batteries have the advantages of high energy density and long service life. They are becoming the mainstream energy storage components in electrical vehicles (EVs) [1-4]. In order to meet the energy demand of EVs, a large number of cells are needed to connect in series and parallel to form a battery pack. However, battery cells can be different due to manufacturing imperfection and aging conditions, there are inevitable differences in the internal resistance, capacity and voltage between cells. It will be more with repeated charging

\footnotetext{
Manuscript received January 7, 2021; revised March 4, 2021; accepted June 2, 2021. This work was supported in part by the National Natural Science Foundation of China under Grant 61703145 , in part by the key scientific and technological projects of Henan Province under Grant 202102210093, 212102210248, and in part by the Fundamental Research Funds for the Universities of Henan Province under Grant NSFRF210332. Recommended for publication by Associate Editor Chaoui, Hicham. (Corresponding author: Xiaozhuo Xu.)

X.W. Guo, J.H. Geng, Z. Liu, X.Z. Xu are with the School of Elec trical Engineering and Automation, Henan Polytechnic University, Jiaozu o, 454000, China (e-mail: gxw@hpu.edu.cn; jxx@vip.126.com; mycutylo ve@foxmail.com; xxz@hpu.edu.cn).

W.P. Cao is with the School of Electrical Engineering and Automation, Anhui University, Hefei 230601, China (e-mail: caowenping@hotmail.com).
}

\footnotetext{
${ }^{1}$ Copyright (c) 2015 IEEE. Personal use of this material is permitted. However, permission to use this material for any other purposes must be obtained from the IEEE

by sending a request to pubs-permissions@ieee.org.
}

and discharging cycles. The discrepancy between individual cells will reduce the usable capacity, lead to excessive heat and even catch fire. To improve the power flow and health conditions of the battery pack, it is necessary to manage the discrepancy in the battery management system (BMS) [5]. The impact of inconsistency on series-connected battery pack are significantly stronger than that on parallel-connected battery pack [6]. Therefore, this paper is set out to investigate the imbalance of series-connected battery pack and to develop a new method to balance the power flow.

Existing research on balancing methods include balancing topologies and control strategies. In terms of the balancing topologies, they can be divided into passive topologies and active topologies [7]. Passive balancing utilizes additional resistors to consume unwanted energy. The method easily causes energy waste and affects the overall thermal balance of the battery pack [8]. In contrast, active balancing uses energy storage elements (e.g. capacitors, inductors, and transformers) to achieve energy transfer [9-10]. It can improve the balancing speed and efficiency as compared to the first topology. The topologies based on switched capacitors were reported in [1112] which are featured with compact size and flexible controllability. However, its balancing efficiency is not high. The topologies based on inductors were reported in [13-15] which have a higher balancing efficiency, but their structure is more complex. It is not conducive to the balancing system volume reduction. LC resonant balancing circuit [16-18] can transfer energy directly between any two cells, but require bulky magnetic components, high-voltage switches, a complex control algorithm, or prolonged balancing time when they are used to balance a pack that has high voltage and high capacity. Balancing topologies based on transformers have the advantages of simple control, high balancing efficiency, and easy isolation. There have been many studies reported in recent decades [19-24]. For example, topologies based on multi- 
winding transformers were developed in [19-21], which have the advantages of transferring energy between any single units, but the problems of large volume and complex structure is more serious. A bi-directional transformer was used to equalize cells in the battery pack [22]. However, the cost and volume of the structure will increase with the number of transformers increases. A modular balancing method using multiwinding transformers [23] reduces the cost and volume compared with the former approach. However, all cells were coupled with the same transformer, and the magnetic leakage problem of the transformer was prominent. A forward-flyback transformer was used in [24] to achieve the energy transfer between any single cell, in which the flyback transformer was applied to replace the demagnetizing circuit required by the forward transformer. However, each cell requires two MOSFETs and one transformer winding, the number of components is large. Moreover, its control is also more complicated.

Existing research on balancing control have mainly focused on the determination of consistency index. Because it is easier to set up an experimental platform and it is common to use the battery voltage as the index of inconsistency [16-24], this paper uses the voltage as the index of balancing inconsistency.

Based on the above analysis, combined with the characteristics of flyback converter, such as simple structure and high conversion efficiency, this paper proposes a balancing topology based on flyback converter, which has the characteristics of simple structure, simple control, fast balancing speed and easy expansion. Moreover, a dual-objective hybrid balancing control strategy is developed to address extreme voltage levels (the highest voltage and the lowest voltage) simultaneously in one sampling period, to improve the balancing speed.

The content of this article is arranged as follows. The Section II introduces the structure and working principle of the novel topology, and the Section III analyzes and calculates the main parameters. In Section IV, a dual-objective hybrid balancing control strategy is proposed and explained in detail. The Section $\mathrm{V}$ analyzes the balancing performance through simulation. The Section VI is the experimental content, which verifies the effectiveness of the new balancing method. The Section VII gives the conclusion of this article.

\section{StRucture AND OPERATIONAL PRINCIPLE}

This Section first introduces the structure of the proposed topology, and then analyzes its working principle in detail.

\section{A. Balancing Topology}

Fig. 1 shows the schematic circuit diagram of the proposed topology. Each cell is sequentially labeled $\mathrm{B}_{1}, \mathrm{~B}_{2}, \mathrm{~B}_{3}, \ldots, \mathrm{B}_{\mathrm{n}}$, and each MOSFET is labeled $S_{0}, S_{1}, S_{2}, \ldots, S_{2 n+2}$. The balancing circuit includes $2 n+3$ MOSFETs, $2 n+3$ diodes, two flyback converters and a resistance-capacitance-diode (RCD) buffer circuit.

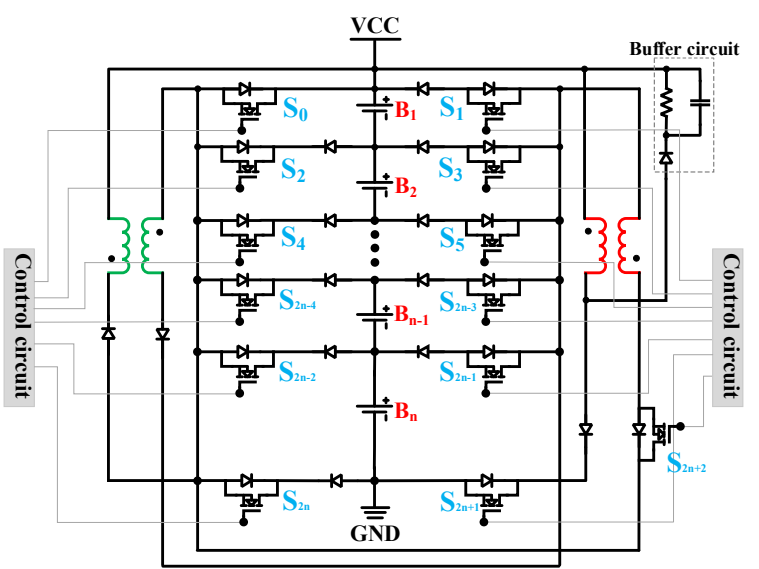

Fig. 1. Structure diagram of the balancing topology.

In Fig.1, the flyback converter on the left is used to balance the cell with the highest voltage. The upper and lower ends of the primary side are connected to the left and right MOSFETs of each cell, respectively. The secondary side is connected to the battery pack through a MOSFET and a diode. The flyback converter on the right is used to balance the cell with the lowest voltage. The primary side is connected to the battery pack through a MOSFET and a diode, and the upper and lower ends of the secondary side are connected to the left and right MOSFETs of each cell. The left and right sides of the balancing circuit have a certain symmetry. The flyback converter on the right needs an additional MOSFET $\mathrm{S}_{2 \mathrm{n}+2}$. It turns off when the flyback converter on the left works and turns on when the flyback converter on the right works. Because the primary side of the right flyback converter is connected with the whole battery pack, when the battery pack completes charging the converter, the leakage spike voltage caused by leakage inductance needs to be reduced to protect the MOSFETs. In this paper, an RCD buffer circuit with simple structure [25] is used to reduce the spike voltage on the MOSFET, which is connected in parallel with the primary side of the right flyback converter.

\section{B. Operational Principle}

This section considers the balancing topology of four cells as the example to specifically introduce its working principle. Fig. 2 shows the working principle of the four-cell series balancing topology. It is assumed that the voltage of $\mathrm{B}_{3}$ is the highest, and 
$\mathrm{B}_{2}$ is the lowest, the battery pack inconsistency satisfies the working conditions of the balancing circuit.

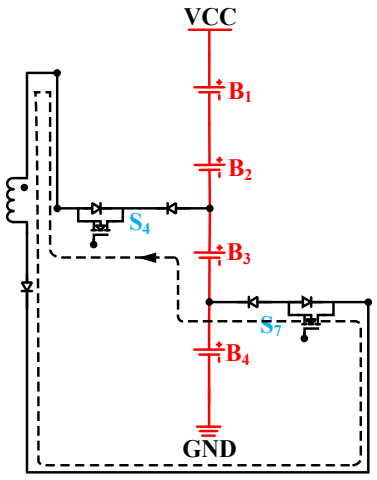

(a)

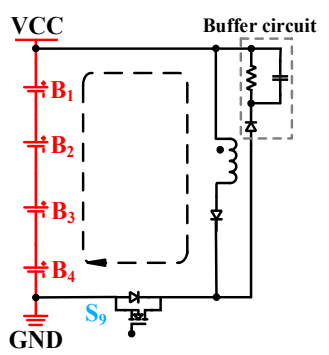

(c)

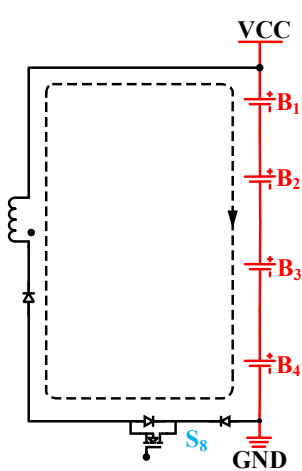

(b)

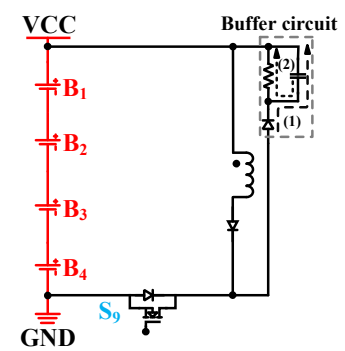

(d)

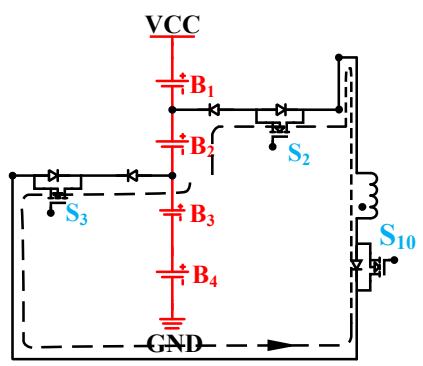

(e)

Fig. 2. Balancing principle. (a) Charging the primary inductor of the left converter. (b) Discharging the secondary inductor of the left converter. (c) Charging the primary inductor of the right converter. (d) Absorbing the leakage inductance spike voltage. (e) Discharging the secondary of the right converter.

In the balancing process. First, the converter on the left discharges $\mathrm{B}_{3}$, and then the converter on the right charges $\mathrm{B}_{2}$. The working process of the converter on the left is divided into two stages, and during the two stages, MOSFET $\mathrm{S}_{10}$ is turned off. Fig. 2(a) is the first stage, MOSFETs $\mathrm{S}_{4}$ and $\mathrm{S}_{7}$ corresponding to $\mathrm{B}_{3}$ are turned on, $\mathrm{B}_{3}$ charges the primary inductor, the primary current rises linearly, and the induced electromotive force is "positive up and negative down". Fig. 2(b) is the second stage, MOSFETs $\mathrm{S}_{4}$ and $\mathrm{S}_{7}$ are turned off, and MOSFET $S_{8}$ is turned on. Since the inductive current cannot change abruptly, the primary side will generate an induced electromotive force "negative up and positive down". The polarity of the induced electromotive force coupled to the secondary inductance is "positive up and negative down". This electromotive force of the secondary inductor will charge the whole battery pack to realize the discharge balancing of the highest voltage cell $\mathrm{B}_{3}$.

The working process of the right converter can be divided into three stages, MOSFET $\mathrm{S}_{10}$ is turned on. Fig. 2(c) is the first stage, MOSFET $S_{9}$ is turned on, and the whole battery pack charges the primary inductor. The primary current increases linearly, and the voltage polarity is "positive up and negative down". Fig. 2(d) is the second stage, MOSFET $\mathrm{S}_{9}$ is turned off. The capacitor in the RCD absorption circuit absorbs leakage inductance energy stored in the flyback convert and then the energy is consumed by the resistor, thus reducing the voltage impact on the primary MOSFET and ensuring the safe operation of the circuit. Fig. 2(e) is the third stage, MOSFETs $\mathrm{S}_{3}$ and $\mathrm{S}_{4}$ are turned on. Similarly, the secondary inductor of the right converter will generate an induced electromotive force "positive up and negative down" to charge the lowest voltage cell $\mathrm{B}_{2}$.

\section{DetERMINATION OF The TOPOlOGY PARAMETERS}

The key parameters in the topology mainly include the inductance, the turn ratio of the converters, and the duty ratio of the switch signals. In addition, both flyback converters must work in discontinuous current mode to prevent hysteresis saturation.

First, calculate the parameters of the left converter. When the primary MOSFETs are turned off, an induced electromotive force "positive up and negative down" is generated on the secondary side, while an induced voltage "negative up and positive down" is generated on the primary side. This is the reflected voltage $V_{\mathrm{f}}$.

$$
V_{\mathrm{f}}=N \times\left(V_{n}+2 V_{D}\right)
$$

where $N$ is the turns of the converter, $V_{n}$ is the voltage of the battery pack, $V_{\mathrm{D}}$ is the conduction voltage drop of the diode.

The voltage drop on the primary MOSFET is approximately $V_{n}+V_{\mathrm{f}}$. To reduce the voltage stress of the primary MOSFET, the design of the turn ratio should not be too large. After the turn ratio is determined, the primary and secondary inductance must also be determined. The expression of the maximum balancing current is given by:

$$
I_{\mathrm{P}}=\frac{D T\left(V_{i}-3 V_{\mathrm{D}}\right)}{L_{\mathrm{P}}}
$$

where $D$ is the proportion of the primary side inductive current rise time, $T$ is the control signal period, $L_{\mathrm{P}}$ is the primary inductance. 
According to the required maximum balancing current and the selected switching frequency, the $L_{\mathrm{P}}$ can be obtained.

$$
L_{\mathrm{P}}=\frac{D\left(V_{i}-3 V_{\mathrm{D}}\right)}{I_{\mathrm{P}} f}
$$

where $V_{i}$ is the voltage of the balanced target, $f$ is the switching frequency.

Then, the secondary inductance can be obtained according to:

$$
L_{\mathrm{S}}=L_{\mathrm{P}} / N^{2}
$$

The expression of the primary current in one balancing period is:

$$
i_{\mathrm{P}}=\frac{V_{i}-3 V_{\mathrm{D}}}{L_{\mathrm{P}}} t, \quad 0 \leq t<D T
$$

The expression of the secondary current is:

$$
i_{\mathrm{S}}= \begin{cases}N \frac{V_{i}-3 V_{\mathrm{D}}}{L_{\mathrm{P}}} D T-N^{2} \frac{V_{n}+2 V_{\mathrm{D}}}{L_{\mathrm{P}}}(t-D T), & D T \leq t<\left(D+D^{\prime}\right) T \\ 0, & \left(D+D^{\prime}\right) T \leq t<T\end{cases}
$$

where $D^{\prime}$ is the secondary side current fall time ratio. The converter must work in the discontinuous current mode, that is, it can be reset. When $t=T, t>\left(D+D^{\prime}\right) T$, and then:

$$
D<\frac{L_{\mathrm{P}}\left(V_{n}+2 V_{\mathrm{D}}\right)}{N L_{\mathrm{S}}\left(V_{i}-3 V_{\mathrm{D}}\right)+L_{\mathrm{P}}\left(V_{n}+2 V_{\mathrm{D}}\right)}
$$

According to the volt-second principle, which is:

$$
\left(V_{i}-3 V_{\mathrm{D}}\right) \times D \times T=\frac{1}{N} \times\left(V_{n}+2 V_{\mathrm{D}}\right) \times D^{\prime} \times T
$$

$D^{\prime}$ can be calculated:

$$
D^{\prime}=\frac{N D\left(V_{i}-3 V_{\mathrm{D}}\right)}{V_{n}+2 V_{\mathrm{D}}}
$$

Balancing efficiency is also an important performance parameter of the balancing topology. In one balancing period, the energy $W_{x}$ released by the high-energy cell $\mathrm{B}_{\mathrm{n}}$ is the energy in the primary inductor plus the energy consumed in the primary balancing path:

$$
W_{x}=\int_{0}^{D T}\left(i_{\mathrm{p}} L_{\mathrm{p}} \frac{d i_{\mathrm{p}}}{d t}+3 V_{\mathrm{D}} i_{\mathrm{P}}+3 R_{\mathrm{DS}} i_{\mathrm{P}}^{2}\right) d t
$$

By combining Eqs. (10), (2) with (5):

$$
W_{x}=\left(\frac{1}{2}+\frac{3 V_{\mathrm{D}}}{2\left(V_{i}-3 V_{\mathrm{D}}\right)}+\frac{D R_{\mathrm{DS}}}{f L_{\mathrm{P}}}\right) \frac{D^{2}\left(V_{i}-3 V_{\mathrm{D}}\right)^{2}}{f^{2} L_{\mathrm{P}}}
$$

The energy $W_{y}$ transferred to the battery pack is the energy released by the secondary inductor minus the energy consumed in the secondary balancing path. The expression is as follows:

$$
W_{y}=\int_{0}^{D T} i_{\mathrm{P}} L_{\mathrm{P}} \frac{d i}{d t} d t-\int_{D T}^{\left(D+D^{\prime}\right) T}\left(2 V_{\mathrm{D}} i_{\mathrm{S}}+R_{\mathrm{DS}} i_{\mathrm{S}}{ }^{2}\right) d t
$$

By combining Eqs. (2), (4), (5), (6) with (9):

$$
\begin{aligned}
& W_{y}=\left(\frac{1}{2}-\frac{\left(2 N^{2}-N^{4}\right) V_{\mathrm{D}}}{V_{n}+2 V_{\mathrm{D}}}-\frac{\left(3 N^{3}+N^{7}-3 N^{5}\right) D R_{\mathrm{DS}}}{3 L_{\mathrm{P}} f} \frac{V_{i}-3 V_{\mathrm{D}}}{V_{n}+2 V_{D}}\right) \\
& \times \frac{D^{2}\left(V_{i}-3 V_{\mathrm{D}}\right)^{2}}{f^{2} L_{\mathrm{P}}}
\end{aligned}
$$

According to the change in energy before and after in one balancing period, the balancing efficiency $\eta_{\mathrm{L}}$ of the left converter can be obtained as:

$$
\begin{aligned}
& \eta_{\mathrm{L}}=\frac{W_{\mathrm{y}}}{W_{\mathrm{x}}}=\left[\frac{3 f L_{\mathrm{P}}\left(V_{n}+2 V_{\mathrm{D}}\right)-\left(12 N^{2}-6 N^{4}\right) V_{\mathrm{D}} f L_{\mathrm{P}}}{\left.3 f L_{\mathrm{P}} V_{i}+6 D R_{\mathrm{DS}} V_{i}-18 D R_{\mathrm{DS}} V_{\mathrm{D}}\right)\left(V_{n}+2 V_{\mathrm{D}}\right)}\right. \\
& \left.-\frac{-\left(6 N^{3}+2 N^{7}-6 N^{5}\right) D R_{\mathrm{DS}}\left(V_{i}-3 V_{\mathrm{D}}\right)}{\left.3 f L_{\mathrm{P}} V_{i}+6 D R_{\mathrm{DS}} V_{i}-18 D R_{\mathrm{DS}} V_{\mathrm{D}}\right)\left(V_{n}+2 V_{\mathrm{D}}\right)}\right] \times\left(V_{i}-3 V_{\mathrm{D}}\right)
\end{aligned}
$$

From Eq. (14), it can be seen that the factors that affect the balancing efficiency mainly include the turn ratio, inductance value, frequency, duty cycle, diode turn-on voltage drop, and voltage of the balancing object and the entire battery pack. In the specific design process, the turn ratio and the maximum balancing current must be determined first, and the primary and secondary inductances are calculated on this basis. The second is to select the switching frequency. Due to the strong uncertainty of the voltage of the balancing object, this paper does not consider specific balancing efficiency.

The difference between the parameter calculations of the right converter and the left converter is that the right converter needs an RCD buffer circuit. The parameters of the RCD buffer circuit can be designed [25] according to the following Eq. (15).

$$
\left\{\begin{array}{l}
P_{\mathrm{RCD}}=\frac{1}{2} L_{\mathrm{K}} I_{\mathrm{P}}^{2} \frac{V_{\mathrm{RCD}}}{V_{\mathrm{RCD}}-V_{\mathrm{f}}} f \\
R=\frac{2 V_{\mathrm{RCD}}\left(V_{\mathrm{RCD}}-V_{f}\right)}{L_{\mathrm{K}} I_{P}^{2} f} \\
\Delta V_{\mathrm{RCD}}=\frac{V_{\mathrm{RCD}}}{C R f}
\end{array}\right.
$$

where $V_{\mathrm{RCD}}$ is the voltage of the absorption capacitor, the leakage inductance of the converter is $L_{\mathrm{K}}, P_{\mathrm{RCD}}$ is the loss of the RCD buffer circuit.

\section{Dual-obJective Hybrid Balancing StRategy}

This paper innovatively proposes a dual-objective hybrid balancing strategy, the specific content of which is as follows. 


\section{A. Setting Balancing Index}

The maximum single voltage and the minimum single voltage in the battery pack are taken as balanced targets. Set the voltage of each cell as $U_{i}$, the maximum voltage as $U_{\max }$, the minimum voltage as $U_{\min }$, and the average as $U_{\text {ave }}$ :

$$
\begin{aligned}
& D_{0}=U_{\text {max }}-U_{\text {ave }} \\
& D_{1}=U_{\text {ave }}-U_{\text {min }}
\end{aligned}
$$

Set the critical parameter for the operation of the balancing circuit as $V_{\text {ref. }}$

\section{B. Balancing Process}

The balancing process includes a number of single voltage sampling periods, and each sampling period includes a number of balancing periods.

In every sampling period, if:

$$
\left\{\begin{array} { l } 
{ D _ { 0 } > V _ { r e f } } \\
{ D _ { 1 } \leq V _ { r e f } }
\end{array} \text { or } \left\{\begin{array}{l}
D_{1}>V_{r e f} \\
D_{0}>V_{r e f} \\
D_{0} \geq D_{1}
\end{array}\right.\right.
$$

the inconsistency of the high-voltage cell satisfies the balancing condition, the control circuit discharges the cell with the highest voltage. If:

$$
\left\{\begin{array} { l } 
{ D _ { 1 } > V _ { \text { ref } } } \\
{ D _ { 0 } \leq V _ { \text { ref } } }
\end{array} \text { or } \left\{\begin{array}{l}
D_{1}>V_{\text {ref }} \\
D_{0}>V_{\text {ref }} \\
D_{1}>D_{0}
\end{array}\right.\right.
$$

the inconsistency of the low-voltage cell satisfies the balancing condition, the control circuit charges the cell with the lowest voltage.

At the end of each sampling period, the sampling circuit redetects the voltage of each cell. If the operating condition of the balancing circuit is satisfied, the balancing circuit works. If not, the balancing circuit does not work. The dual-objective hybrid balancing strategy flow for each sampling period is shown in Fig. 3.

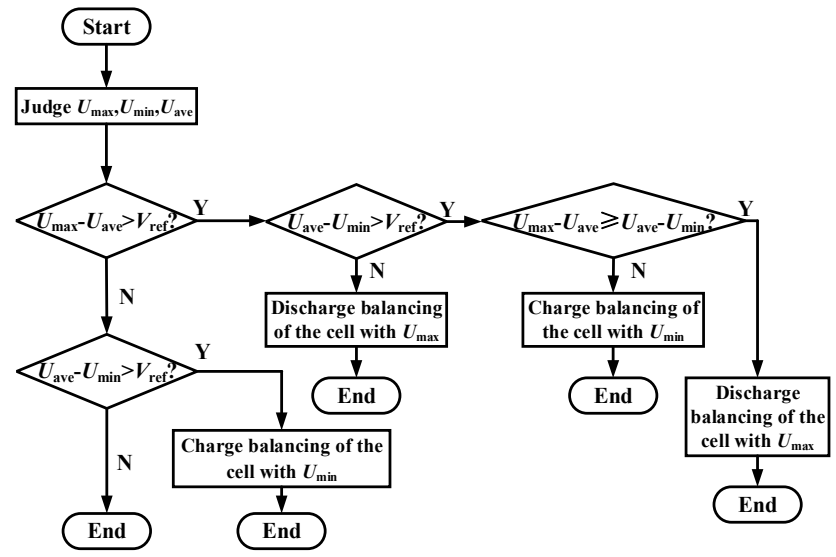

Fig. 3. Flow chart of the dual-objective hybrid balancing strategy.
The balancing control of the charging process and the discharging process are combined into one. In the charging or discharging balancing process, not only is the single cell with a higher voltage discharged but also the cell with a lower voltage is charged, and finally, the balancing speed is improved. In addition, under the same balancing speed condition, the balancing current is reduced, thereby reducing the influence of the balanced process on the performance of the single cell and the loss of the switches.

\section{Balancing Performance Analysis}

This section mainly includes balancing speed analysis, balancing efficiency analysis and balancing topology cost analysis. The analysis of balancing speed and efficiency takes the balancing of the shelved state as the example.

\section{A. Analysis of balancing speed}

Balancing speed analysis includes speed comparison analysis and analysis of the influence of switching frequency on balancing speed. Take the same transformer-based topologies $[19,20,22]$ as the object of balancing speed comparison, and a 4-cell battery pack for example. the simulation models are built in MATLAB/Simulink, and the parameters are shown in Table I. The simulation results are shown in Fig. 4.

TABLE I

SiMUlation PaRAMETERS OF THE BaLANCING MODEL

\begin{tabular}{ccc}
\hline \hline Parameters & Symbol & Value \\
\hline Initial voltage of & $\mathrm{V}$ & $3.988 \mathrm{~V}, 3.984 \mathrm{~V}$ \\
each cell & & $3.979 \mathrm{~V}, 3.974 \mathrm{~V}$ \\
Balanced threshold & $\mathrm{V}$ & $0.005 \mathrm{~V}$
\end{tabular}

PWM1, PWM2

duty cycle

$\alpha, \alpha^{\prime} \quad 45 \%, 55 \%$

Switching frequency $\quad f \quad 5 \mathrm{KHz}, 10 \mathrm{kHz}, 20 \mathrm{KHz}$

Diode voltage drop $\quad \Delta V \quad 0.4 \mathrm{~V}$

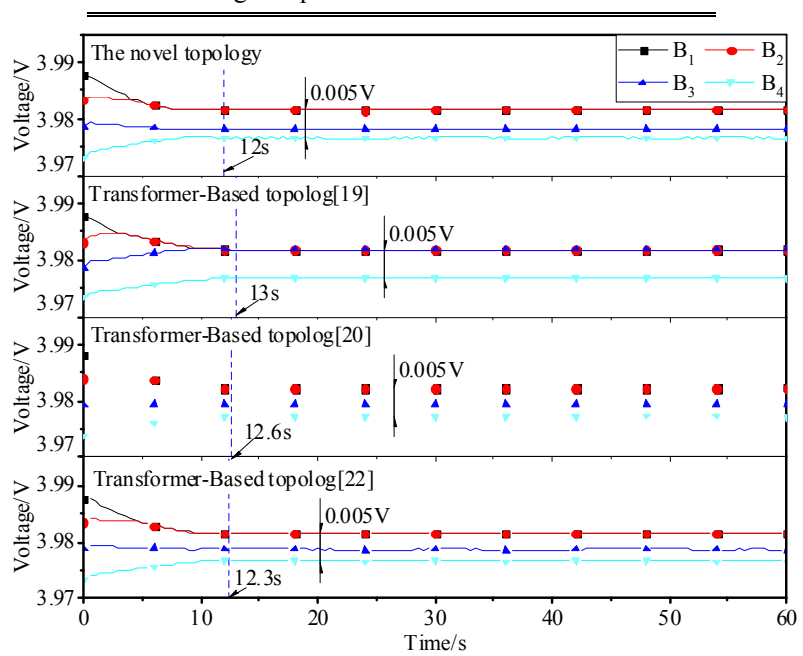

(a) 


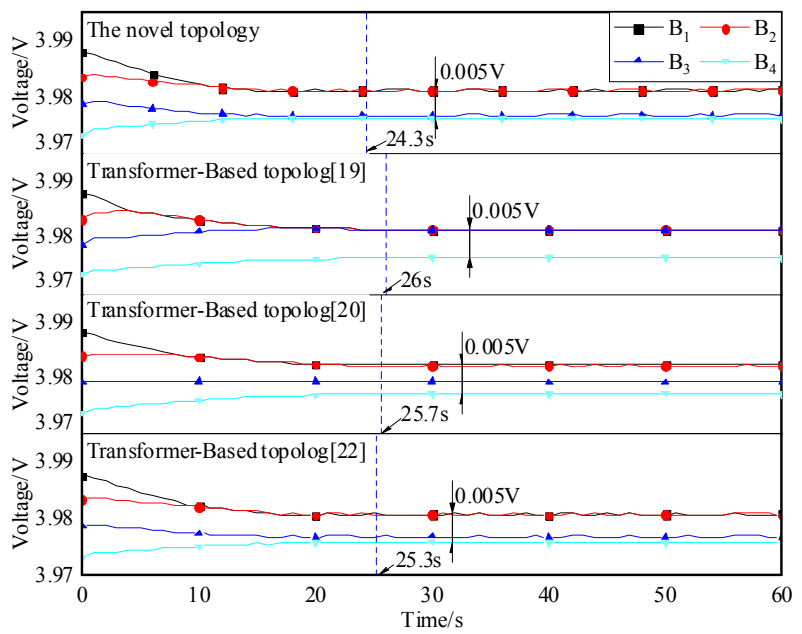

(b)

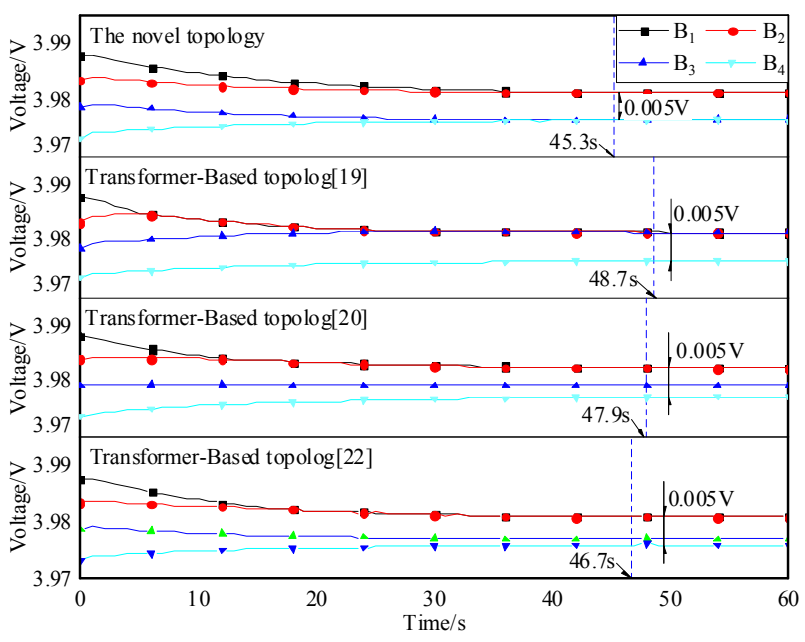

(c)

Fig.4. Simulation results of different switching frequencies. (a) $5 \mathrm{kHz}$. (b) $10 \mathrm{kHz}$. (c) $20 \mathrm{kHz}$.

It can be seen from Table I and Fig. 4 that the initial maximum voltage difference is $0.014 \mathrm{~V}$, which meets the balancing circuit start condition, and the balancing starts. When the balancing ends, the maximum voltage difference is maintained at $0.005 \mathrm{~V}$, which meets the balancing stop condition.

In addition, it can be seen from Fig. 4 that, compared with the transformer topology [19,20,22], the balancing speed of the new balancing topology has been improved. Compared with the topology in [19], the balancing speed is increased by $7.69 \%$, $6.54 \%$ and $6.98 \%$ respectively. The main reason is that the balancing in [19] is based on two adjacent cells as the balanced goal, rather than directly balancing the highest or lowest cell. Compared with the topology in [20], the balancing speed is increased by $4.76 \%, 5.45 \%$, and $5.64 \%$ respectively. The main reason is that the balancing path [20] includes not only transformers, but also energy storage devices such as capacitors and inductors, instead of directly transferring energy through the transformers. Compared with the topology in [22], the balancing speed is increased by $2.44 \%, 3.95 \%$ and $3.00 \%$ respectively. The main reason is that the balancing energy transfer process [22] involves cells that do not need to be balanced, which affects the balancing speed. It should be noted that, under different initial conditions, the ratio of the increase in the balancing speed is different, but the conclusion that the balancing speed has increased is certain. when the switching frequency is $5 \mathrm{kHz}$, the overall balancing speed is the fastest. This is because under the condition of constant duty cycle, the lower the switching frequency, the greater the balancing current per cycle, and the more power transferred. Although the lower the switching frequency, the greater the balancing current. But the greater the balancing current, the greater the effect of the balancing process on each cell. When the switching frequency is $20 \mathrm{kHz}$, the balancing current is reduced, which is beneficial to reduce the influence of the balancing process on each cell. Comprehensively considering the influence of the balancing process on the battery cell and the balancing speed, the balancing experiment set the switching frequency to $10 \mathrm{kHz}$ in this paper.

\section{B. Balancing efficiency analysis}

Balancing efficiency analysis includes efficiency comparison analysis and analysis of the influence of switching frequency on balancing efficiency. To analyze the balancing efficiency based on the simulation model, first define the balancing efficiency based on the change in the battery power before and after the balancing. the balancing efficiency is determined by dividing the total cell change power by the total discharge power [26,27], the detail mathematical expressions can be found in [27].

Taking the same transformer-based topologies [19, 20, 22] as the comparison object, refer to Table I to set the simulation parameters, and the simulation results of balancing efficiency are shown in Table II.

TABLE II

SIMULATION RESULTS OF BALANCING EFFICIENCY

\begin{tabular}{ccccc}
\hline \hline Operating frequency & $2 \mathrm{kHz}$ & $5 \mathrm{kHz}$ & $10 \mathrm{kHz}$ & $20 \mathrm{kHz}$ \\
\hline $\begin{array}{c}\text { Transformer } \\
\text { topology [19] }\end{array}$ & $99.78 \%$ & $99.86 \%$ & $99.83 \%$ & $99.80 \%$ \\
$\begin{array}{c}\text { Transformer } \\
\text { topology[20] }\end{array}$ & $99.77 \%$ & $99.86 \%$ & $99.83 \%$ & $99.80 \%$ \\
$\begin{array}{c}\text { Transformer } \\
\text { topology [22] }\end{array}$ & $99.90 \%$ & $99.95 \%$ & $99.93 \%$ & $99.92 \%$ \\
New topology & $99.89 \%$ & $99.92 \%$ & $99.92 \%$ & $99.91 \%$ \\
\hline \hline
\end{tabular}

As shown in Table II, it can be observed that, when the switching frequency is $5 \mathrm{kHz}$, all topologies have the highest efficiency. However, when the switching frequency decreases to $2 \mathrm{kHz}$, the efficiency also decreases because of the increasing 
copper and core losses of the transformer. Particularly, the balancing efficiency dramatically decreases as the switching frequency increases to $20 \mathrm{kHz}$ due to the larger switching loss.

In addition, the factors that cause the difference in balancing efficiency mainly include the number of switching tubes and windings through which the balancing current flows. The number of switching tubes and windings included in the balancing current flow path in $[19,20]$ is greater than that of the new topology, and the balancing efficiency is lower than the new topology.

The number of switching tubes and windings included in the balancing current flow path in [22] is less than that of the new topology, and the balancing efficiency is higher. This conclusion is consistent with the simulation results.

\section{Balanced topology cost analysis}

Taking the 18650 ternary lithium battery pack composed of 4 cells, 8 cells, and 12 cells as examples. The specific analysis results are shown in Fig. 5. Set the unit price of various devices according to the literatures [16,22]. Component cost per unit (\$): MOSFET (M) (0.2), Diode (D) (0.03), Winding (W) (0.2), Transformer Core (T) (0.5), Inductor (L) (0.25), Capacitor (C) (0.25), and Transformer (T) (3).

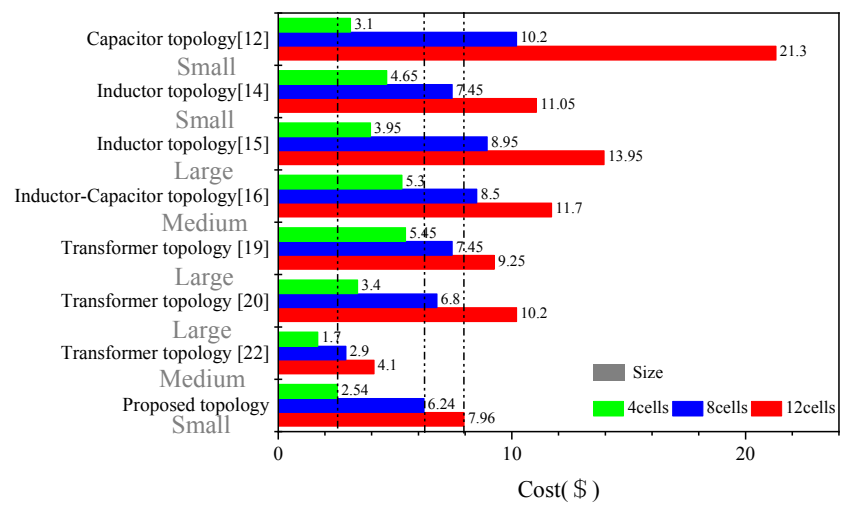

Fig. 5. Comparison of balancing topology cost.

It can be seen from Fig. 5 that compared with the most mainstream topologies, the cost of the new balancing topology has been reduced, and the size of topology is small. In the topology of literature [12], although the number of switching tubes used is small, the number of switching capacitors is large, which is not conducive to reducing the volume of the balancing topology, and the cost is high. In the topology of literature [14], the energy storage device has only one inductor, which is beneficial to reduce the volume of the balancing system, but the large number of switch tubes is not conducive to the reduction of the cost of the balancing system. In the literature [15], each single cell in the topology is equipped with three switching tubes and one inductor, which is not only costly, but also not conducive to the reduction of the balancing system volume. In the literature [16], although the energy storage device has only one inductor and one capacitor, it requires more switch tubes, which results in a higher cost of the balancing system and no significant reduction in volume. In the literature [19], although the number of switching tubes used in the topology is small, it requires a large number of transformers, and each transformer requires three windings, which is unfavorable to balance the cost and volume reduction of the topology. In the literature [20], the number of switching tubes required for the topology is approximately equal to the number of switching tubes for the new topology, but the transformer structure is too complex, with many windings, and energy storage devices also include capacitors and inductors. Not only is it not conducive to reducing the volume of the balancing system, but it also increases the cost of the system. In the topology of literature [22], compared with the new topology, although the cost is reduced, the number of windings is larger, and the reduction of the balancing system volume is not used. with the increase of the number of cells, the multi-winding structure increases the volume of the converter, but the leakage inductance, mutual inductance and magnetization loss of the multi-winding converter will become more prominent, which greatly improves the design difficulty of the converter.

Comprehensive analysis shows that the new topology energy storage device only needs two single-winding transformers regardless of the number of cells, which is conducive to the reduction of the balancing system volume. Although the number of diodes used in the topology is large, the price of the diodes is much cheaper than that of the switching tube, which helps to balance the cost reduction of the topology. The new topology in this paper has obvious advantages in the volume and cost of the balancing system.

\section{EXPERIMENTAL VERIFICATION}

This section first describes the experimental parameters, and then analyzes the experimental results in detail.

\section{A. Balancing Experiment Parameters}

A balancing experimental platform using a four-cell series battery pack is built, as shown in Fig. 6, and the balancing experiment parameters are shown in Table III. The control signals corresponding to the charging and discharging process of the left converter are PWM1, PWM2. Right converter are PWM3, PWM4. 


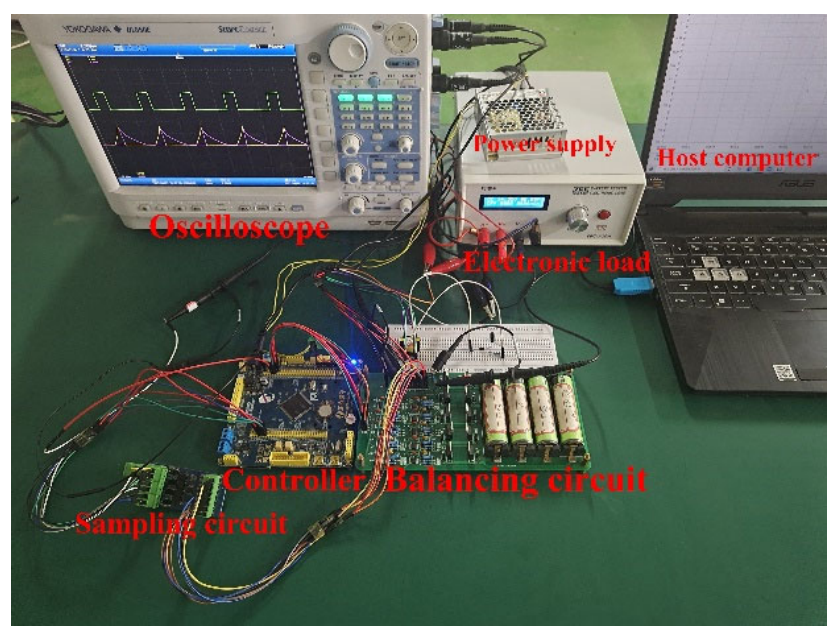

Fig. 6. Balancing experiment platform.

TABLE III

BALANCING EXPERIMENTAL PARAMETERS

\begin{tabular}{cc}
\hline \hline Parameters & Specifications \\
\hline Rated Capacity & $3.2 \mathrm{Ah}$ \\
PWM1 period/duty cycle & $10 \mathrm{kHz} / 75 \%$ \\
PWM2 period/duty cycle & $10 \mathrm{kHz} / 25 \%$ \\
PWM3 period/duty cycle & $10 \mathrm{kHz} / 25 \%$ \\
PWM4 period/duty cycle & $10 \mathrm{kHz} / 75 \%$ \\
Balancing current of left converter & $0.4 \mathrm{~A}$ \\
Balancing current of right converter & $1.5 \mathrm{~A}$ \\
Balancing accuracy & $\Delta \mathrm{V}<0.05 \mathrm{~V}$ \\
Left/right converter turn ratio & $1: 1$ \\
Inductance of primary and secondary & $70 \mu \mathrm{H}$ \\
side of left converter & $50 \mu \mathrm{H}$ \\
Inductance of primary and secondary & $0.4 \mathrm{~V}$ \\
side of right converter & $0.44 \mu \mathrm{F} / 100 \Omega$ \\
Diode conduction voltage drop & \\
Capacitance/Resistance
\end{tabular}

\section{B. Balancing Experiment Results and Analysis}

The balancing experiment includes the verification of the balancing function of the converters and the verification of the balancing effect.

\section{1) The Verification of the Converters' Balancing Function}

Fig. 7 shows the balancing experiment waveforms of the left converter. In one control signal period, in Fig. 7(a), balancing target charges the converter firstly, the primary current rises linearly, and then, the flyback converter charges the whole battery pack, the secondary current decreases linearly. The current peak is 0.4 A. Fig. 7(b) shows the voltage change of the four cells. During the first stage, the highest voltage cell charges the primary inductor, and the highest voltage drops first. After charging is completed, the voltage rises slightly due to the polarization effect of the lithium battery. During the second stage, the secondary inductor charges the whole battery pack. The voltage of the four cells first rises as a whole, and it decreases due to the polarization effect when the charging current is zero. Throughout the process, the highest voltage decreases and approaches the average value.

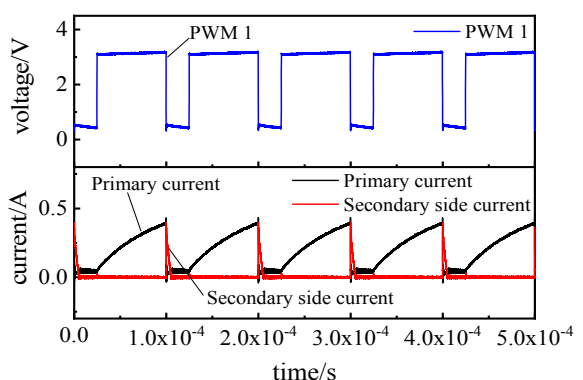

(a)

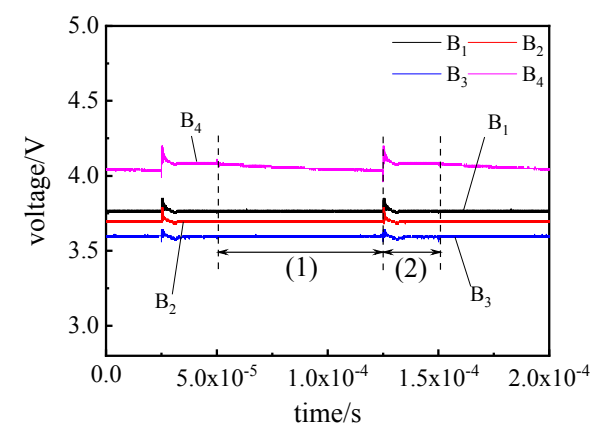

(b)

Fig. 7. Left converter balancing experimental waveforms. (a) PWM1 and balancing current. (b) Battery voltage change during one control signal period.

Fig. 8 shows the balancing experiment waveforms of the right converter. In one control signal period, in Fig. 8(a), the whole battery charges the converter firstly, the primary current rises linearly. And then, the converter charges the lowest voltage cell, the secondary current decreases linearly. The peak value of the current is 1.5 A. In Fig. 8(b), the battery pack charges the primary inductor during the first stage, and the voltage of the four cells first decreases as a whole. After charging is completed, due to the polarization effect, the voltage of each cell rises again. During the second stage, the secondary inductor charges the lowest voltage cell, its voltage rises firstly and then decreases due to the polarization effects of the lithium battery.

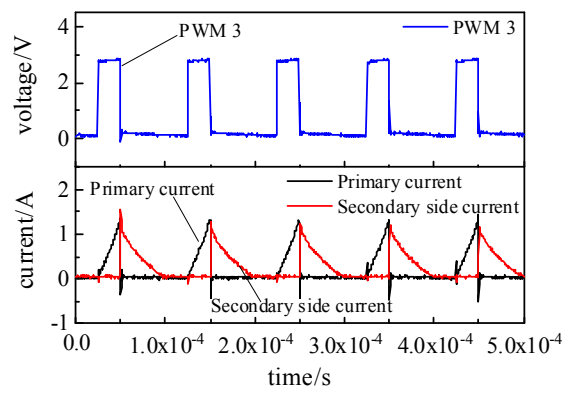

(a) 


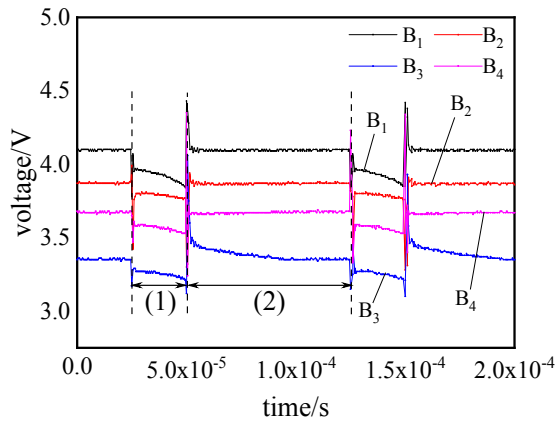

(b)

Fig. 8. Right converter balancing experimental waveforms. (a) PWM3 and balancing current. (b) Battery voltage change during one control signal period.

\section{2) The Verification of the Balancing Effect}

After the functional verification of the balancing topology is completed, the balancing effect needs to be verified, including the charging process, discharging process, and dynamic chargedischarging process. The balancing stop threshold is set to $0.05 \mathrm{~V}$, and the discharge or charge current of the battery pack is $1 \mathrm{~A}$. the waveforms of the balancing results are shown in Fig. 9. The voltage variation of each cell during the balancing process is shown in Table IV. The dynamic balancing experiment includes the charging process, discharging process and shelved state. The battery pack charges with a current of 1 A for 60 minutes firstly, then discharges with a current of $1 \mathrm{~A}$ for 60 minutes, and finally is shelved for 30 minutes.

TABLE IV

THE VOLTAGE VARIATION OF EACH CELL

\begin{tabular}{|c|c|c|c|}
\hline Working state & $\begin{array}{l}\text { Charging } \\
\text { state }\end{array}$ & $\begin{array}{l}\text { Discharging } \\
\text { state }\end{array}$ & $\begin{array}{r}\text { Dynamic } \\
\text { balancing }\end{array}$ \\
\hline $\begin{array}{c}\text { Each cell } \\
\text { voltage before } \\
\text { balancing }(\mathrm{V})\end{array}$ & $\begin{array}{c}3.631, \\
3.491,3.569, \\
3.774\end{array}$ & $\begin{array}{c}3.802, \\
3.693,3.840, \\
4.027\end{array}$ & $\begin{array}{c}3.788,3637, \\
3.733,4.010\end{array}$ \\
\hline $\begin{array}{l}\text { Voltage range } \\
\text { before balancing } \\
\text { (V) }\end{array}$ & 0.310 & 0.334 & 0.373 \\
\hline $\begin{array}{c}\text { Each cell } \\
\text { voltage after } \\
\text { balancing }(\mathrm{V})\end{array}$ & $\begin{array}{c}3.846, \\
3.823,3.836, \\
3.871\end{array}$ & $\begin{array}{c}3.513, \\
3.494,3.524, \\
3.543\end{array}$ & $\begin{array}{c}3.650, \\
3.613,3.644, \\
3.660\end{array}$ \\
\hline $\begin{array}{l}\text { Voltage range } \\
\text { after balancing } \\
\text { (V) }\end{array}$ & 0.048 & 0.049 & 0.048 \\
\hline $\begin{array}{l}\text { Balanced time } \\
\quad(\min )\end{array}$ & 140 & 140 & 150 \\
\hline
\end{tabular}

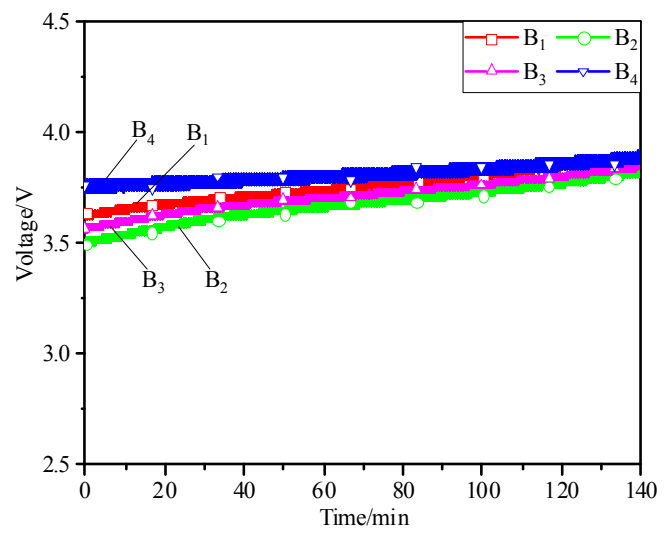

(a)

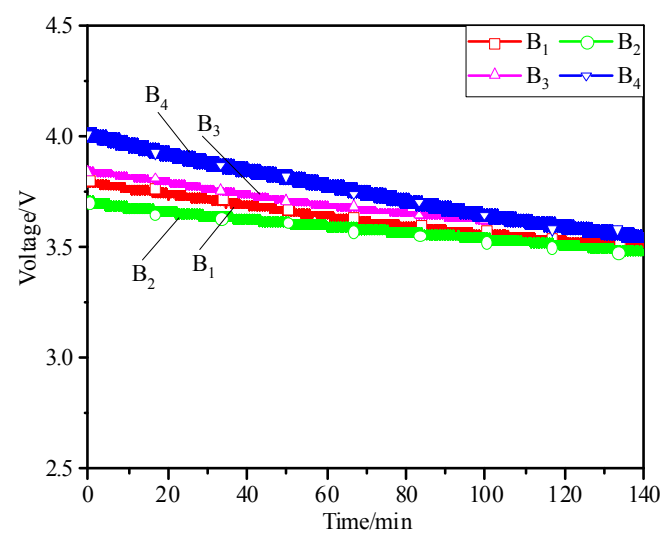

(b)

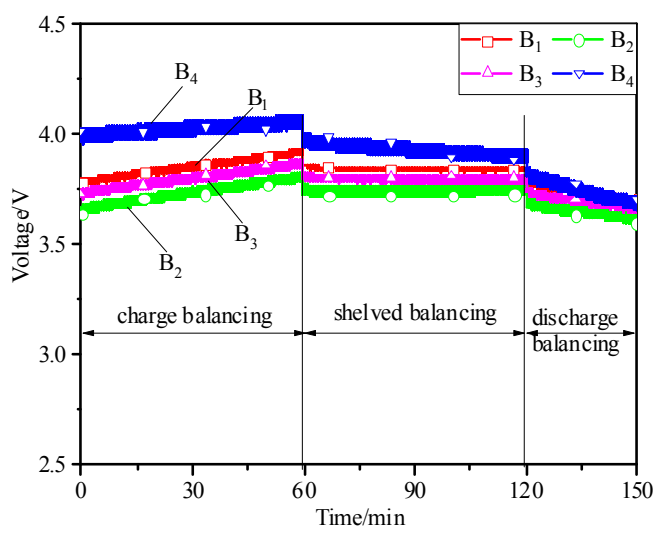

(c)

Fig. 9. Balancing experiments results. (a) Experiments results for charging state. (b) Experiments results for discharging state. (c) Experiments results for dynamic balancing.

Based on the above analysis, the novel balancing method based on flyback converter proposed in this paper has a good dynamic and static balancing effect, and can effectively improve the consistency of the new energy vehicle power battery pack. 


\section{CONCLUSION}

A flyback converter-based balancing method for series battery pack is proposed in this paper. The energy storage unit has only two single-winding transformers. The topology is simpler and easier to control than existing methods. It is helpful to reduce the cost of the balancing system. The dual-objective hybrid balancing control strategy combines the balancing of the charging process and the discharging process into one and simultaneously realizes the reduction of the highest voltage and the increase of the lowest voltage during the charging or discharging process in one sampling period. The simulation results show that the new balancing method has higher balancing speed and efficiency, and low cost. Experimental results show that the proposed method has good balancing effects and can significantly improve the consistency of series battery pack.

\section{REFERENCES}

[1] Y. Shang, K. Liu, N. Cui, N.Wang, K. Li, and C. Zhang, "A compact resonant switched-capacitor heater for lithium-ion battery self-heating at low temperatures," IEEE Trans.Power Electron., vol. 35, no. 7, pp. 7134 7144,Jul. 2020.

[2] K. Liu, C. Zou, K. Li, and T. Wik, "Charging pattern optimization for lithium-ion batteries with an electrothermal-aging model," IEEE Trans.Ind. Informat., vol. 14, no. 12, pp. 5463-5474, Dec. 2018.

[3] X. Tang, K. Liu, X.Wang, F. Gao, J. Macro, andW. D.Widanage, "Model migration neural network for predicting battery aging trajectories," IEEE Trans. Transp. Electrification, vol. 6, no. 2, pp. 363-374, Jun. 2020.

[4] R. Xiong, "Core Algorithm of Battery Management System for EVs," Beijing, China: China Machine Press, 14-19 (2018)

[5] Y. Ye, K. W. E. Cheng, Y. C. Fong, X. Xue and J. Lin, “Topology, Modeling, and Design of Switched-Capacitor-Based Cell Balancing Systems and Their Balancing Exploration," IEEE Transactions on Power Electronics, vol. 32, no. 6, pp. 4444-4454, June. 2017.

[6] M. Ye, X. Song, R. Xiong and F. Sun, “A Novel Dynamic Performance Analysis and Evaluation Model of Series-Parallel Connected Battery Pack for Electric Vehicles," IEEE Access, vol. 7, pp. 14256-14265, 2019.

[7] X. Guo, Z. Liu, X. Xu*, etc. "Integrated Balancing Method for SeriesParallel Battery Packs Based on LC Energy Storage," IET Electric Power Applications. vol. 15, no. 5, pp. 579-592, Mar. 2021.

[8] Y. Shang, C. Zhu, Y. Fu and C. C. Mi, “An Integrated Heater Equalizer for Lithium-Ion Batteries of Electric Vehicles," IEEE Transactions on Industrial Electronics, vol. 66, no. 6, pp. 4398-4405, June. 2019.

[9] M. Caspar, T. Eiler and S. Hohmann, "Systematic Comparison of Active Balancing: A Model-Based Quantitative Analysis," IEEE Transactions on Vehicular Technology, vol. 67, no. 2, pp. 920-934, Feb. 2018.

[10] Kiarash Ahi, "Modeling and Control of a Multiphase Modular High Frequency Converter/Inverter for Vehicle Applications," International
Journal of High Speed Electronics and Systems, vol. 27, no. 1840014, pp. 115, Sep. 2018.

[11] Y. Ye and K. W. E. Cheng, "Modeling and Analysis of Series-Parallel Switched-Capacitor Voltage Equalizer for Battery/Supercapacitor Strings," IEEE Journal of Emerging and Selected Topics in Power Electronics, vol. 3, no. 4, pp. 977-983, Dec. 2015.

[12] Y. Shang, C. Zhang, N. Cui, "A Delta-Structured Switched-Capacitor Equalizer for Series-Connected Battery Strings," IEEE Transactions on Power Electronics, vol. 34, no. 1, pp. 452-461, Jan. 2019.

[13] Y. Chen, X. F. Liu, K. F. Hosam, "A Graph-Theoretic Framework for Analyzing the Speeds and Efficiencies of Battery Pack Equalization Circuits," International Journal of Electrical Power \& Energy Systems, vol. 98, pp.85-99, June, 2018.

[14] S. Lee, K. Lee, Y. Choi, "Modularized Design of Active Charge Equalizer for Li-Ion Battery Pack," IEEE Transactions on Industrial Electronics, vol. 65, no. 11, pp. 8697-8706, Nov. 2018.

[15] S. Wang, S. Yang, W. Yang, "A New Kind of Balancing Circuit with Multiple Equalization Modes for Serially Connected Battery Pack," IEEE Transactions on Industrial Electronics, vol. 68, no. 13, pp. 2142-2150, Mar. 2021.

[16] Y. Shang, Q. Zhang, N. Cui, "Multicell-to-Multicell Equalizers Based on Matrix and Half-Bridge LC Converters for Series-Connected Battery Strings," IEEE Journal of Emerging and Selected Topics in Power Electronics, vol. 8, no. 2, pp. 1755-1766, June. 2020.

[17] K. Liu, Z. Yang, X. Tang, “Automotive Battery Equalizers Based on Joint Switched-Capacitor and Buck-Boost Converters" IEEE Transactions on Vehicular Technology, vol. 69, no. 11, pp. 12716-12724, Nov. 2020.

[18] Y. Yu, R. Saasaa, A. A. Khan and W. Eberle, "A Series Resonant Energy Storage Cell Voltage Balancing Circuit," IEEE Journal of Emerging and Selected Topics in Power Electronics, vol. 8, no. 3, pp. 3151-3161, Sep. 2020.

[19] Y. Li, J. Xu, X. Mei and J. Wang, “A Unitized Multiwinding TransformerBased Equalization Method for Series-Connected Battery Strings," IEEE Transactions on Power Electronics, vol. 34, no. 12, pp. 11981-11989, Dec. 2019.

[20] Y. Shang, S. Zhao, Y. Fu, B. Han, P. Hu and C. C. Mi, "A Lithium-Ion Battery Balancing Circuit Based on Synchronous Rectification,” IEEE Transactions on Power Electronics, vol. 35, no. 2, pp. 1637-1648, Feb. 2020.

[21] Z. Zhang, H. Gui, D. Gu, Y. Yang and X. Ren, “A Hierarchical Active Balancing Architecture for Lithium-Ion Batteries," IEEE Transactions on Power Electronics, vol. 32, no. 4, pp. 2757-2768, Apr. 2017.

[22] Y. Shang, N. Cui, C. Zhang, "An Optimized Any-Cell-to-Any-Cell Equalizer Based on Coupled Half-Bridge Converters for SeriesConnected Battery Strings," IEEE Transactions on Power Electronics, vol. 34, no. 9, pp. 8831-8841, Sep. 2019.

[23] Y. Shang, B. Xia, C. Zhang, N. Cui, J. Yang and C. Mi, "A Modularization Method for Battery Equalizers Using Multiwinding Transformers," IEEE Transactions on Vehicular Technology, vol. 66, no. 10, pp. 8710-8722, Oct. 2017. 
[24] Y. Chen, X. Liu, Y. Cui, J. Zou and S. Yang, “A MultiWinding Transformer Cell-to-Cell Active Equalization Method for Lithium-Ion Batteries with Reduced Number of Driving Circuits," IEEE Transactions on Power Electronics, vol. 31, no. 7, pp. 4916-4929, July 2016.

[25] F. Liu, "Design and Application of Switching Power Supply," Beijing, China: Electronics Industry Press,214-215 (2014)

[26] Y. Shang, B. Xia, F. Lu, C. Zhang, N. Cui, and C. Chris Mi, "A SwitchedCoupling-Capacitor Equalizer for Series-Connected Battery Strings," IEEE Transactions on Power Electronics, vol. 32, no. 10, pp. 7694-7706, Oct, 2017.

[27] L. Liu, B. Xu, Z. Yan, W. Zhou, Y. Li, “A Low-Cost Multi-winding Transformer Balancing Topology for Retired Series-Connected Battery String”, IEEE Transactions on Power Electronics, vol. 36, no. 5, pp. 49314936, May, 2021.

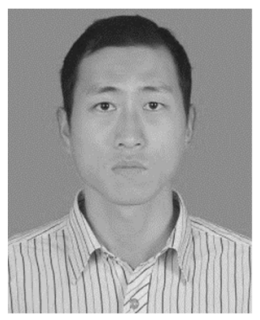

Xiangwei Guo received his M.S. degree in power engineering from Henan Polytechnic University in 2012, Jiaozuo, China. He received Ph.D. degree in Power Electronics from the South China University of Technology, Guangzhou, China in 2016.

He joined the School of Electrical Engineering and Automation, Henan Polytechnic University in 2016 as an Assistant Professor. He is a member of the IEEE. He has published one book and more than 30 articles, and holds more than 10 Chinese inventions. His primary research interests include power electronics and their applications in battery management systems.

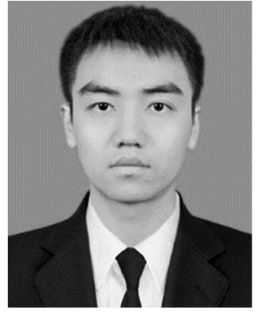

Jiahao Geng was born in Jincheng, Shanxi Province, China in 1996. He received a bachelor's degree in electrical engineering from Henan Polytechnic University in 2018 and is currently pursuing a master's degree at Henan Polytechnic University.

His research interests include energy management for lithium-ion battery, especially the research of battery balancing topology and control strategy.

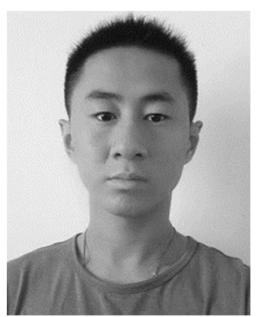

Zhen Liu received the B.S. degree in the School of Machinery and Power Engineering from Henan Polytechnic University, Jiaozuo, China in 2015. He is currently pursuing the M.S. degree in the School of Electrical Engineering and
Automation from Henan Polytechnic University, Jiaozuo, China.

His research interest includes electric vehicle battery management system and power electronics and power drives.

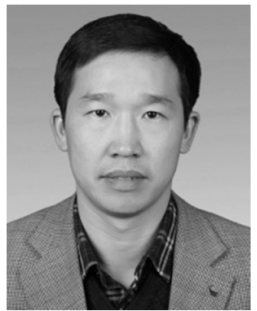

Xiaozhuo Xu was born in Shangchen, Xingyang, China in 1981. He received the B.S., M.S. and the Ph.D. degrees in electrical engineering from Henan Polytechnic University, Jiaozuo, China, in 2003, 2006 and 2016, respectively.

He joined the School of Electrical Engineering and Automation, Henan Polytechnic University in 2006 as an Assistant Professor. Since 2016, he has been the Director of R \& D with the Henan Engineering Research Center of Direct Drive Ropeless Elevators. He is a member of the IEEE. He has published two books and more than 30 articles, and holds more than 20 Chinese inventions. His research interests include electrical machine design, intelligent control, and fault diagnosis, and innovation linear motor applications.

Dr. XU was a recipient of Science and Technology Progress Awards of Henan Province, China, in 2015 and 2016, and the China National Coal Association Patent Award in 2015.

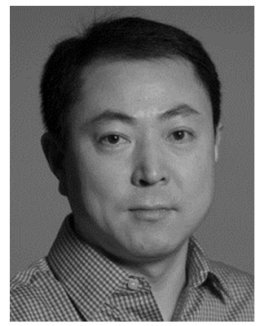

Wenping Cao (Senior Member, IEEE) received the B.Eng. in Electrical Engineering from Beijing Jiaotong University, Beijing, China, in 1991, and the Ph.D. degree in Electrical Machines and Drives from the University of Nottingham, Nottingham, UK, in 2004.

$\mathrm{He}$ is currently a Chair Professor of Electrical Power Engineering with Aston University, Birmingham, UK, and also a Distinguished Professor at the School of Electrical Engineering and Automation, Anhui University, China. His research interests include fault analysis and condition monitoring of electrical machines and power electronics.

Prof. Cao is the Chairman for the Industrial Electronics Society, IEEE UK and Ireland Section, and also a "Royal Society Wolfson Research Merit Award" holder, UK. 